\title{
Only a minority of patients in the urological emergency unit need urgent urology care
}

\author{
Žana Saratlija Novaković, Davor Librenjak
}

Department of Urology, University Hospital Split, Split, Croatia

Corresponding author:

Žana Saratlija Novaković Department of Urology

University Hospital Split

Šoltanska 1, 21000 Split

Croatia

saratlijanovakovic.zana@gmail.com

Tel.: + 38521557775

Fax.: + 38521464554

Received: 5 May 2013

Accepted: 25 February 2014

Copyright (c) 2014 by

Academy of Sciences and Arts

of Bosnia and Herzegovina.

E-mail for permission to publish:

amabih@anubih.ba

\begin{abstract}
Objective. To present patients who were examined, monitored and admitted at the urological emergency unit (UEU) at the University Hospital, Split during the summer and winter of 2010 and to establish who of them were really in need of immediate urological care. Methods. A retrospective study of patients and diagnoses of patients examined at the UEU was undertaken during two winter and two summer months 2010. We compared the total number of patients, the number of patients with urological issues, patients with urological emergencies, patients with non-urological issues, patients who were briefly monitored at the UEU, and patients admitted to the urology department, within these two periods. Descriptive statistic and chi squared tests were used. Results. During the winter period 465 patients were examined at the UEU and during the summer 733 patients. During the summer period there were statistically more urological issues $\left(\chi^{2}=12.3 ; \mathrm{p}=0.005\right)$ and urological emergencies $\left(\chi^{2}=4.14 ; \mathrm{p}=0.042\right)$ while in the winter period there were more non-urological issues and more patients were monitored at the UEU $\left(\chi^{2}=33.9 ; \mathrm{p}<0.001\right)$. The most common diagnoses are: renal colic and urine retention, in both periods. Only $8 \%$ of patients in both the winter and summer periods were admitted to hospital after examination at the UEU, which represents the actual number of patients who needed immediate urological care. Conclusion. Of all the patients examined at the UEU, only a fraction constituted real, life-threatening urological emergencies. Primary care physicians and general emergency departments should be more educated in urological emergencies so that they can resolve more nonemergency patients themselves.
\end{abstract}

Key words: Emergency urology, Renal colic, Urine retention.

\section{Introduction}

The urology emergency unit (UEU) should be managing patients with appropriate diagnoses. Before coming to the UEU, every patient should be examined by a primary care physician or emergency medicine physician. These physicians should provide immediate care to patients, such as catheterization of the urinary bladder, or give analgesic therapy for renal colic $(1,2)$. Only a fraction of urology patients have life threatening conditions, which require immediate urologic intervention (2). Some urological emergencies have seasonal variations, and in different parts of the world different physicians 
or other medical staff deal with emergency urological issues (3-5).

The overall number of emergency admissions to hospital has increased over recent years, exerting a significant strain on the ability of many hospitals to undertake elective work. Lower thresholds for referral to hospital and the greater tendency of patients to present themselves to emergency departments with 'surgical' problems are likely to be significant factors in the increase of the burden on hospital departments (6).

Therefore we decided to investigate how many patients at UEU really do need urological intervention, how many of them need hospital admission or are monitored for a few hours at the UEU. We were also interested in differences between the winter and summer periods in the structure of UEU patients according to their discharge diagnosis.

\section{Methods}

A retrospective study of urological emergency department admissions was conducted. The number of patients and diagnoses of patients examined at the UEU were analyzed during two winter months (JanuaryFebruary 2010) and two summer months (July-August 2010). The working hours of this department are $4 \mathrm{pm}$ to $8 \mathrm{am}$. Diagnoses upon discharge were noted for each patient examined at the UEU within these periods. Patients with polytrauma, patients examined during regular the Urology Department working hours of 8 am $-4 \mathrm{pm}$, and patients examined in other hospital departments were not included in this analysis. The UEU is located in the University Hospital. A urologist works in this unit with or without a resident.

We collected patient data, analyzed how many of them had urological issues, which of them were really an emergency, how many patients were monitored at the UEU, and how many of them were hospitalized in our department for further evaluation and treatment. After that we compared the data between the two months in the winter and summer periods.

\section{Statistical analyses}

Data were analyzed using the program Statistica 7.0 (StatSoft Inc, Tulsa, OK, USA). Descriptive statistics were used where appropriate. Additionally, we used the chi squared test. The significance level was set at $\mathrm{p}<0.05$.

\section{Results}

At the UEU of the University Hospital Split, 465 patients were examined during January and February 2010 and 733 patients during July and August of the same year (Table 1). About $30 \%$ of patients were not examined in an emergency medicine unit or by a primary care physician before presenting at the UEU. We also analyzed the number of urological diagnosis, non-urological diagnosis and urological emergencies throughout these months (Table 1).

Significantly more patients with urological issues presented at the UEU during the summer period ( $95 \%$ vs. $89 \%$ ) than during the winter period $\left(\chi^{2}=12.3 ; \mathrm{p}=0.005\right)$. Also, during the summer period, there were significantly more urological emergencies ( $76 \%$ vs. $70 \%)$ than during the winter pe$\operatorname{riod}\left(\chi^{2}=4.14 ; \mathrm{p}=0.042\right)$. Patients came to the UEU without evident urological issues during the winter period 2.2 times more frequently ( $11 \%$ vs. $5 \%)$ than during the summer period.

Some patients were monitored in the UEU for a few hours after examination. Short-term monitoring was indicated in these patients because they had received analgesics, or they were waiting for the results of diagnostics. In the winter period there 
Table 1 Distribution of patients at the urology emergency unit

\begin{tabular}{lll}
\hline \multirow{2}{*}{ Patients } & Time of the year, 2010 & \\
\cline { 2 - 3 } & January and February & July and August \\
\hline Total $(\mathrm{n})$ & 465 & 734 \\
Urological issues, $\mathrm{n}(\%)$ & $415(89.3)$ & $695(94.7)$ \\
Urological emergencies, $\mathrm{n}(\%)$ & $291(70.1)$ & $526(75.7)$ \\
Non-urological issues, $\mathrm{n}(\%)$ & $50(10.8)$ & $38(5.2)$ \\
\hline
\end{tabular}

were 174 (37\%) monitored patients, and 161 (22\%) such patients in the summer period. During the winter period we monitored 1.7 times more patients at the UEU than during the summer $\left(\chi^{2}=33,9 ; p<0.001\right)$, (Figure 1$)$.

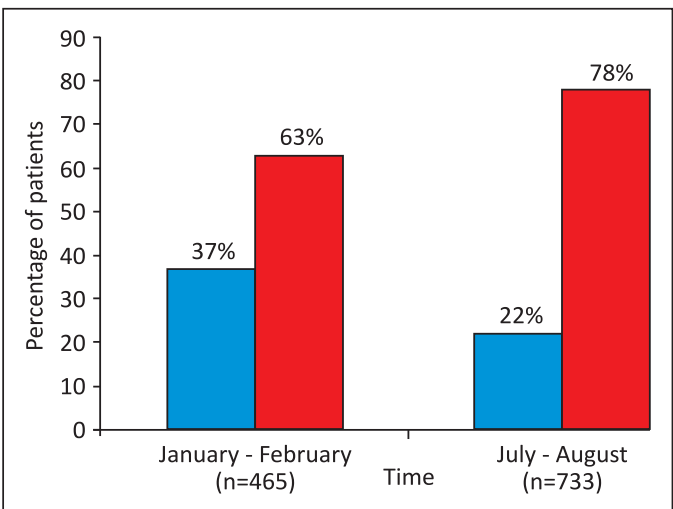

Figure 1 The percentage of patients monitored in the UEU after initial examination. The blue bars denote the percentage of monitored patients, and the red bars indicate patients who were discharged from the UEU after examination.
The most common urological emergencies treated at the UEU in the analyzed periods were renal colic, urine retention, hematuria and acute prostatitis (Table 2).

There was no significant difference between the number of patients according to their final diagnosis and the time of year when they were examined $\left(\chi^{2}=4.18\right.$; $\mathrm{p}=0.309$ ), although the absolute values of patients presenting with renal colic, urine retention, hematuria, acute prostatitis and obstructive uropathies were higher during the summer period (Table 2).

Among all the patients only 57/733 $(7.8 \%)$ were admitted to the urology department for further evaluation and treatment during the summer period, and 38/465 $(8.2 \%)$ during the winter period. There was no difference in frequencies in diagnoses between these two groups $\left(\chi^{2}=0.06 ; \mathrm{p}=0.799\right)$.

Table 2 Urological emergencies treated at the urology emergency unit

\begin{tabular}{lll}
\hline \multirow{2}{*}{ Urologic emergencies } & \multicolumn{2}{l}{ Number of patients during the specified time of year 2010 } \\
\cline { 2 - 3 } & January and February 291/465 & July and August 526/734 \\
\hline Renal colic & 133 & 202 \\
Urine retention & 66 & 127 \\
Hematuria & 29 & 55 \\
Acute prostatitis & 27 & 60 \\
Obstructive uropathies & 16 & 34 \\
Complicated uroinfections & 6 & 10 \\
Minor genital lesions & 4 & 15 \\
Renal trauma & 4 & 15 \\
Testis torsion & 4 & 5 \\
Paraphimosis & 2 & 3 \\
\hline
\end{tabular}




\section{Discussion}

The daily work of the urological profession in our hospital certainly includes many "urgent" patients encountered in the urological emergency unit. Most patients present with two main conditions: renal colic and urinary retention. Uncomplicated renal colic (90\%) and most cases of retention should be resolved by emergency physicians or primary care physicians (2).

Our results show that this is not the case in our setting. Renal colic and urinary retention were the two most common diagnoses with which patients presented at our UEU, which is located in a university hospital. The frequencies of diagnoses in our study were comparable to the results of previous studies in urological emergency care units $(6,7)$. In our study, only $8 \%$ of patients in both the winter and summer periods were admitted to hospital after examination at the UEU. A case study at a French university teaching hospital showed that $15.6 \%$ of patients at their UEU were admitted to the hospital. Diagnoses encountered at the French UEU did not include a high number of renal colics, as in our case, which means perhaps that the patients seen at their UEU were highly selected before being referred to the UEU (8).

We very rarely encountered patients at the UEU who had previously received any analgesics for renal colic or patients in whom somebody had attempted catheterization for urinary retention. This makes us wonder what went wrong with the previous steps in patient care - i.e. the primary care physician and general emergency department. The question for our health care system is how can we promptly help our patients and save costly resources.

A significant number of patients were referred to the UEU without having evident urological symptoms. Our hospital is in a tourist area so we noticed a larger number of emergency patients during the summer period, but during the winter period we diagnosed more patients at our UEU without urological issues. We monitored more patients during the winter period at the UEU, for which we do not have a plausible explanation. The number of patients examined at the UEU and then admitted to our department for further treatment did not differ between the summer and winter. Office based physicians increasingly rely on specialised emergency departments to evaluate complex patients with potentially serious problems, rather than managing these patients themselves.

Strategies are needed to contain emergency-department attendance. Quality of care in general practice might influence the use of emergency departments, including management of patients with chronic conditions and access to consultations. A study by Baker et al. showed that satisfaction with telephone access to primary physicians may predict rates of attendance at emergency departments. Consideration should be given to improving access to some general practices to reduce the use of emergency care resources (9).

In this setting, interventions, such as education and implementing protocols for primary care physicians, which would prevent unnecessary specialist referrals, would be beneficial.

\section{Conclusion}

Indeed, only a minority of patients at the UEU need urgent urology care, suggesting the need for changes in organization when treating such patients. Seasonal variations between summer and winter periods due to the overall number of patients, urological emergencies and non-emergencies were as we expected. 
Acknowledgement: We are grateful to Dr. Livia Puljak for helping with the manuscript. Thanks to Vesna Capkun for statistical advice.

Authors' contributions: Conception and design: ŽSN, DL; Acquisition, analysis and interpretation of data: ŽSN, DL; Drafting the article ŽSN; Revising it critically for important intellectual content: ŽSN, DL.

Conflict of interest: The authors declare that they have no conflict of interest.

\section{References}

1. Samm BJ, Dmochowski RR. Urologic emergencies: Conditions affecting the kidney, ureter, bladder, prostate, and urethra. Postgrad Med. 1996;100:177-80.

2. Rosenstein D, McAninch JW. Urologic emergencies. Med Clin North Am. 2004;88:495-518.

3. Chen YK, Lin HC, Chen CS, Yeh SD. Seasonal variations in urinary calculi attacks and their association with climate: a population based study. J Urol. 2008;179:564-9.
4. Goriunov VG, Davidov MI. The effect of meteorological factors on the incidence of acute urinary retention. Urol Nefrol (Mosk). 1996;1:4-7.

5. Ward ST, Mithen RJ, Mohamed MS, Mufti GR. Seasonal variation in emergency referrals to a Surgical Assessment Unit. Int J Clin Pract. 2009;63:121-5.

6. Campbell WB, Lee EJ, Van de Sijpe K, Gooding J, Cooper MJ. A 25-year study of emergency surgical admissions. Ann R Coll Surg Engl. 2002;84:273-7.

7. Fall B, Diao B, Fall PA, Diallo Y, Sow Y, Ondongo AA, et al. Urological emergencies at the Dakar university teaching hospital: epidemiological, clinical and therapeutic features. Prog Urol. 2008;18:650-3.

8. Mondet F, Chartier-Kastler E, Yonneau L, Bohin D, Barrou B, Richard F. Epidemiology of urological emergencies in a teaching hospital. Prog Urol. 2002;12:437-42.

9. Baker R, Bankart MJ, Rashid A, Banerjee J, Conroy $S$, Habiba $M$, et al. Characteristics of general practices associated with emergency-department attendance rates: a cross-sectional study. BMJ Qual Saf. 2011;20(11):953-8. 